\title{
SOBRE O PAPEL (HISTÓRICO) DA CRÍTICA
}

\author{
CRISTIAN BORGES revê a recepção do filme Viagem ao fim do \\ mundo, de Fernando Coni Campos, a partir de comentários \\ de Jean-Claude Bernardet
}

No dia 22 de junho de 2011, o crítico, roteirista e professor aposentado da ECAUSP, Jean-Claude Bernardet, postou em seu blog na internet uma espécie de mea culpa em relação a um filme de 1968, Viagem ao fim do mundo, dirigido por Fernando Coni Campos. [1] No texto, Bernardet narra a forma como recentemente retomou contato com a obra e revela sua estupefação ao dar-se conta de que não havia escrito nada sobre o filme, nem na época de seu lançamento, nem depois:

\begin{abstract}
Hoje tenho certeza de que, quando vi o filme pela primeira vez, percebi que não havia nada semelhante no panorama cinematográfico brasileiro, que ele abria perspectivas em direção ao cinema-ensaio, à possibilidade de elaborar ensaios em filmes, que o pensamento no cinema não precisava se ater à ficção, que o pensamento no cinema podia recorrer à ficção entre outros instrumentos. Quando revi o filme neste mês de junho de 2011, fiquei petrificado: como era possível que eu não tivesse escrito sobre esse filme?
\end{abstract}

Segue-se, então, uma espécie de auto-enquete através da qual o autor tenta retroceder no tempo em busca de possíveis razões para tamanho disparate. Acabamos compartilhando sua perplexidade: como poderia um crítico tão arguto e atuante quanto ele ter deixado passar em branco um filme como esse? Em meio a tantos filmes que ele diz ter defendido na mesma época - como O bandido da luz vermelha, de Rogério Sganzerla, Triste Trópico, de Arthur Omar, e outros tantos que lhe "pareciam renovadores" -, por que justo esse teria ficado de fora, sem que ele o houvesse destacado, lançando alguma luz sobre um filme ousado, porém facilmente fadado ao esquecimento? Teria a ditadura e o AI-5 concorrido para essa ausência em sua produção crítica, devido às dificuldades pelas quais passou nesse período? Fato é que sobre esse filme ele nada escreveu e, sem conseguir "reconstituir as circunstâncias" que o levaram a essa inação, confessa: "revendo-o, senti um enorme buraco na minha carreira de crítico por não ter escrito e por não ter participado da sua carreira”.

1. Disponível em: http://jcbernardet.blog.uol.com.br/arch2011-06-19_2011-06-25.html 
Essa atitude, a um só tempo humilde e consciente de sua responsabilidade, me fez pensar a respeito do papel preponderante da crítica através dos tempos: quantas obras e artistas não deixaram de "contar", de fato, para seus contemporâneos ou mesmo para épocas vindouras devido ao total desprezo ou à simples indiferença da produção crítica; e, ao contrário, quantas outras só resistiram por causa do olhar generoso lançado por algum crítico que, por razões diversas, as destacou da multidão de obras - ainda que algumas delas talvez nem merecessem tal destaque?

Sabemos que somente graças ao trabalho de recuperação empreendido por Forkel, Zelter e Mendelssohn a obra de Johann Sebastian Bach pôde voltar a ser ouvida e interpretada, ganhando enfim a posteridade, muito tempo após a morte do grande compositor alemão. Da mesma forma, sabemos que sempre haverá obras e artistas caindo de vez no esquecimento ou ressurgindo dele, qual uma fênix renascida de suas próprias cinzas. Mas o que me parece particularmente notável na atitude de Bernardet é que ele assuma, "43-44 anos depois", parte da culpa por essa obra importante - dentre tantas outras - permanecer ignorada. Fosse pelas adversidades sócio-políticas pelas quais passavam o país e o autor na época da realização do filme, ou então por sua aversão de "crítico de esquerda, na militância contra a ditadura" a qualquer filme que abordasse de modo tão direto e visceral uma reflexão a respeito da religião e do sagrado, o fato é que Bernardet reconhece sua inação como sendo "uma falha grave" em sua carreira e se culpabiliza por isso, comprometendo-se a "colaborar para a reabilitação do filme":

\footnotetext{
Não vejo outro motivo consistente para ter relegado o filme ao

esquecimento, ao meu esquecimento, senão a incapacidade em que eu estive de assimilar a sua angústia religiosa. E com isso ter ignorado toda a sua potencialidade estética. Pior do que isso: não ignorei, pois me lembro de ter percebido essa potencialidade, simplesmente a rejeitei e tranquei o filme a sete chaves por causa da sua religiosidade.
}

Em 21 de setembro de 2011, logo após haver assistido, pela primeira vez, ao filme de Fernando Coni Campos - realmente impressionante -, e lido o texto de Bernardet em seu blog - quase três meses depois de o mesmo ter sido postado, e ainda tocado por sua atitude e sua auto-exposição -, decidi enviar-lhe a seguinte mensagem por e-mail:

Caríssimo Jean-Claude,

Gostaria de comentar seu post a respeito do belo filme de Fernando Coni Campos, Viagem ao fim do mundo, no qual, ao fazer uma espécie de "mea culpa", por não haver dado ao filme a devida importância na época de seu lançamento, você destaca não apenas um filme importante - ignorado em seu tempo e esquecido em seguida -, mas o papel fundamental e delicado 
da crítica de arte (e, neste caso mais específico, de cinema) que pode, por vezes mesmo sem se dar conta, não apenas condenar ou elogiar uma obra, mas lançá-la ao esquecimento por omissão; ou ainda, o que me parece mais louvável: resgatá-la dos escombros, do limbo, tempos depois.

Questão espinhosa, sem dúvida, mas que se coloca - nem que seja apenas para alguns críticos mais ciosos de seu ofício, como sempre foi o seu caso. Pois não se trata aí, absolutamente, de dar sua opinião (de "especialista") sobre tal ou tal obra, que deve ou não ser levada em conta no momento de seu surgimento ou divulgação; mas de uma responsabilidade muito maior dessa crítica mais sutil que recontextualiza, a posteriori, não apenas a obra em questão, mas a si própria no momento de sua omissão - menos restrita, digamos, a uma crítica cotidiana que se contenta muitas vezes em simplesmente lançar comentários apressados no calor da hora, concedendo estrelinhas, bonequinhos dormindo ou aplaudindo etc.

Trata-se, desse modo, de reconhecer o legítimo valor histórico da crítica, tornando-a dinâmica, ativa. Não me refiro aqui ao valor da crítica histórica, nem da história da crítica, ambas congeladas num passado remoto e às vezes até equivocado - como você mesmo assinala no referido post. Refiro-me, antes, à importância histórica no sentido que lhe atribui Walter Benjamin, ao falar da imagem dialética (por exemplo, em alguns trechos do seu livro das Passagens): a recuperação tensa do Ocorrido no Agora, de maneira viva, nunca embalsamada.

O que você deixa transparecer em seu post é a capacidade que possui o crítico - ao menos o verdadeiro crítico, aquele que possui responsabilidade histórica, justamente - de não apenas nos informar sobre o presente, mas também de nos guiar pelo passado, desfazendo injustiças e recuperando das ruínas tesouros à espera de alguma luz, ainda hoje ("sobrevivências", como diria o historiador de arte alemão Aby Warburg).

E pensar que alguns filmes precisam de tão pouco para sobreviver...

Esse gesto do crítico, potencializado hoje em dia pelo imediatismo e pelo vasto alcance proporcionados pela internet, opera um duplo movimento:

- por um lado, o de destacar da profusão, do emaranhado de obras colocadas à disposição aquelas que realmente contam e que mereceriam um olhar mais atento, mais afetuoso por parte do crítico e do público (independentemente da época em que elas teriam sido produzidas) - ressaltando, assim, o papel "pedagógico" do crítico, que o identifica muito mais ao professor, ao educador que ao juiz. Tratase de um crítico que seria, antes, um "anacronista" que um cronista das obras de sua época, trabalhando dentro de um tempo estilhaçado, que poderíamos chamar de anacrônico (no sentido warburguiano), pois se ele acorda com vontade ou necessidade de escrever em seu blog, num jornal ou numa revista, impressa ou 
eletrônica, sobre um filme dos anos 20, dos anos 70 ou de agora, ele tem total liberdade e seu leitor o acompanha nesse "anacronismo" ativo e (por que não?) estimulante, dada a falta de previsibilidade - que é encontrada, por exemplo, nos guias culturais e na crítica cotidiana mais tradicional.

- por outro lado, esse gesto opera um segundo movimento, a meu ver igualmente importante, que é o da autocrítica efetiva, no ato de se posicionar enquanto um agente em movimento, em constante transformação e renovação, passível de se autoanalisar, de se autocriticar ou mesmo de se contradizer. Trata-se aqui de um ato de inteligência aguda, mas também de humildade na exposição de suas próprias deficiências, falhas, imprecisões, apontando ao mesmo tempo para um pensamento sempre aberto, em constante trabalho de reflexão e revisão, nunca fechado, nunca finito.

Mesmo porque, como o próprio Bernardet aponta em seu texto, o filme de Coni Campos "abria perspectivas em direção ao cinema-ensaio, à possibilidade de elaborar ensaios em filmes". Ora, a forma ou o modo "ensaístico" no cinema não era, em 1968, algo tão em evidência quanto hoje. Apesar de o ensaio ser reconhecido como gênero literário desde o século XVI, com a obra de Michel de Montaigne, sua abordagem pelo cinema só seria reconhecida muito recentemente - ainda que fosse praticada há muito mais tempo.[2] Um dos primeiros estudiosos a relacionar de maneira mais direta o cinema à forma ensaística, através de um tipo de filme que ele denominava "forma-meditação", foi Noel Burch, no livro Práxis do cinema, publicado na França em 1969, apenas um ano depois da realização do filme de Coni Campos. Em todo caso, não havia ainda, como passou a haver nos últimos anos, uma discussão tão calorosa e atenta a essa forma híbrida entre a ficção, o documentário e o diário filmado, comumente designada por ensaio fílmico ou filme-ensaio. Daí, talvez, Bernardet ter destacado essa forte característica do filme de Coni Campos somente a posteriori, uma vez que as ferramentas conceituais para tal diagnóstico apresentar-se-iam efetivamente apenas muito mais tarde. O que não impede que ele o reconheça em seu blog como um pioneiro do gênero no Brasil:

Como é possível que, quando dei um curso sobre cinema-ensaio em Porto Alegre, eu não o tenha incluído na programação? Não havia cópia? Então o citasse como um pioneiro do ensaio cinematográfico na filmografia brasileira.

\footnotetext{
2. Vide, por exemplo, alguns filmes vanguardistas dos anos 1920, bem como a noção, elaborada e posta em prática por Sergei Eisenstein, de um "cinema conceitual" que "funciona como estratégia de reflexão sobre o mundo". Cf. MACHADO, Arlindo. "O filme-ensaio". In: MOURÃO, Maria Dora; SAMPAIO, Rafael (org.). Marker: bricoleur multimídia. São Paulo: Centro Cultural Banco do Brasil, 2009.
} 
Enfim, seja como for, o fato é que um grande crítico como Jean-Claude Bernardet - respeitado por obras consideradas célebres e pioneiras na reflexão da produção cultural e cinematográfica brasileira, sobretudo durante os anos 1960 e 1970 revela-se, ainda hoje, antenado e em sintonia com seu tempo, atento aos recursos (informalidade, rapidez, largo alcance, intercâmbio direto com seus leitores, etc.) proporcionados pela internet não apenas como forma contemporânea de prática da crítica, mas também como meio propício ao resgate de uma obra perdida no passado.

CRISTIAN BORGES é professor de cinema da Escola de Comunicações e Artes da USP, doutor em cinema e audiovisual pela Universidade de Paris III, cineasta e organizador de várias mostras. 